\title{
Realism and Anti-Realism about experiences of understanding
}

\author{
Jordan Dodd
}

\section{Philosophical Studies}

An International Journal for Philosophy in the Analytic Tradition

\section{ISSN 0031-8116}

Volume 168

Number 3

Philos Stud (2014) 168:745-767

DOI 10.1007/s11098-013-0155-1

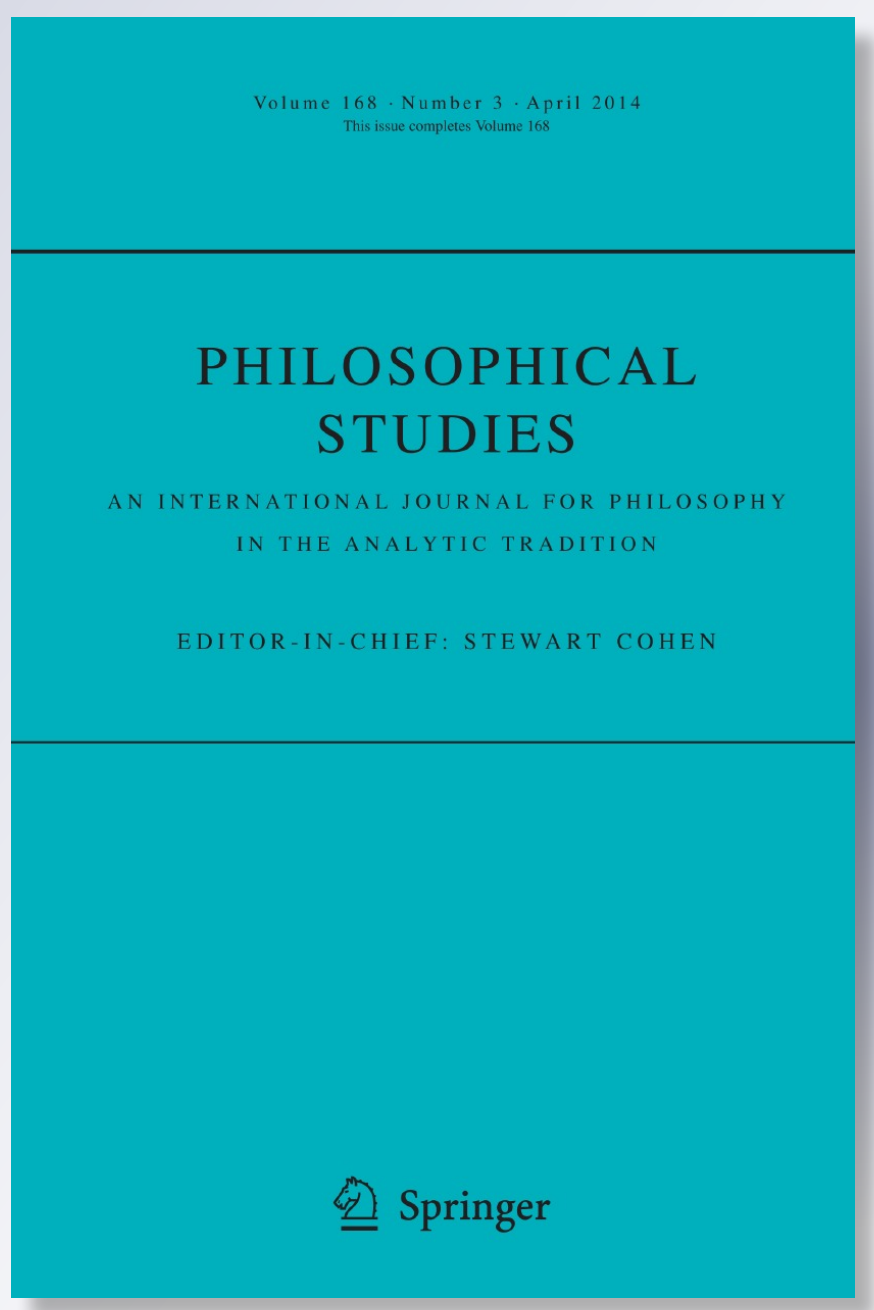


Your article is protected by copyright and all rights are held exclusively by Springer Science +Business Media Dordrecht. This e-offprint is for personal use only and shall not be selfarchived in electronic repositories. If you wish to self-archive your article, please use the accepted manuscript version for posting on your own website. You may further deposit the accepted manuscript version in any repository, provided it is only made publicly available 12 months after official publication or later and provided acknowledgement is given to the original source of publication and a link is inserted to the published article on Springer's website. The link must be accompanied by the following text: "The final publication is available at link.springer.com". 


\title{
Realism and Anti-Realism about experiences of understanding
}

\author{
Jordan Dodd
}

Published online: 21 June 2013

(C) Springer Science+Business Media Dordrecht 2013

\begin{abstract}
Strawson (1994) and Peacocke (1992) introduced thought experiments that show that it seems intuitive that there is, in some way, an experiential character to mental events of understanding. Some (e.g., Siewert 1998, 2011; Pitt 2004) try to explain these intuitions by saying that just as we have, say, headache experiences and visual experiences of blueness, so too we have experiences of understanding. Others (e.g., Prinz 2006, 2011; Tye 1996) propose that these intuitions can be explained without positing experiences of understanding. Call this the debate between Realism and Anti-Realism about experiences of understanding. This paper aims to advance that debate in two ways. In the first half, I develop more precise characterizations of what Realists and Anti-Realists propose. In the second half, I distinguish the four most plausible versions of Anti-Realism and argue that Realism better explains the target intuition than any of them does.
\end{abstract}

Keywords Consciousness - Experiences of understanding ·

Cognitive phenomenology

\section{Introduction}

Imagine Homer and Bart watch a French language commercial. They view the same images, have the same sounds hit their ears, and so on. Suppose, though, that unlike Homer, Bart speaks French. No doubt there are many similarities between the conscious experiences that Homer and Bart have when they watch the commercial.

\footnotetext{
J. Dodd $(\bowtie)$

Department of Philosophy, Carleton University, 3A46 Paterson Hall, 1125 Colonel By Drive, Ottawa, ON K1S 5B6, Canada

e-mail: jordan_dodd@carleton.ca
} 
But does it seem intuitive that there is any difference between what conscious experiences they have when watching the commercial? ${ }^{1}$

Next, imagine Lisa and Apu view a sign written in Hindi. Suppose that although both recognize text written in Hindi as such, only Apu can read Hindi. No doubt there are many similarities between the conscious experiences that Lisa and Apu have as they look at the sign. But does it seem intuitive that there is any difference between what conscious experiences they have while viewing the sign? ${ }^{2}$

Many philosophers have become interested in these sorts of thought experiments. ${ }^{3}$ A minimal agreement seems to exist:

First, all parties seem to agree that if studies were carried out, the statistical norm would be to answer 'Yes' to the above questions. Second, all parties seem to agree that these 'Yes' answers are (defeasible, fallible) evidence that: it can seem intuitive that there is, in some way, an experiential character to Bart and Apu's mental events of understanding their target semantic items that is absent from Homer and Lisa's mental lives.

This second point of agreement-call it 'the target intuition'-needs a few clarifications. One issue is that it uses the concept of experiential character (or, interchangeably, phenomenal character). To say that subject S's mental event E has an experiential character is to say that there is something it is like for $\mathrm{S}$ to have $\mathrm{E}$. This risks simply cashing out jargon with near jargon. But improving on the concept of there-is-something-it-is-like-ness is beyond this essay.

The larger clarifications concern talk of mental events of understanding. We know that the target intuition is about Bart and Apu's mental events of understanding. But it will help to flag some relevant features of these mental events. There are two points to make:

First, there are stronger and weaker necessary conditions that we could put in place for having a mental event of understanding. A stronger condition would require a kind of success. It would say: if at $\mathrm{S}$ is in a mental event of understanding semantic item $\mathrm{C}$, then at $\mathrm{t} \mathrm{S}$ is correctly understanding what $\mathrm{C}$ means. In contrast, a weaker standard would not require success. It would say: if at $\mathrm{t} S$ is in a mental event of understanding $\mathrm{C}$, then at $\mathrm{t}$ there is some $\mathrm{M}$ such that $\mathrm{S}$ is understanding $\mathrm{C}$ as meaning $\mathrm{M}$, even if $\mathrm{C}$ does not mean $\mathrm{M}$. These different standards correspond to factive and non-factive interpretations of the concept of understanding.

Bart and Apu have mental events of understanding no matter which of these standards we use. But what needs flagging is that the target intuition does not depend on that. Specifically, it does not depend on Bart and Apu having mental events of understanding in the stronger, factive sense. Imagine Bart eventually discovers that he badly misunderstands French, so much so that it turns out that he had badly misunderstood the commercial. If this were the case, when Bart viewed

\footnotetext{
1 This case is based on Galen Strawson's Jack and Jacques example (Strawson 1994, pp. 5-6). If you think that Bart doesn't speak French, you haven't seen the episode titled 'The Crepes of Wrath' (The Simpsons Episode 11, 1990).

2 This example is based on one involving Cyrillic texts from Peacocke (1992, p. 89).

3 For example, Siewert (1998, 2011), Strawson (1994, 2005, 2011), Prinz (2006, 2007, 2011), Bayne (2009), Siegel (2006), Robinson (2005), Pitt (2004), Horgan and Tienson (2002), and Tye (1996).
} 
the commercial he would have only had mental events of understanding in the weaker, non-factive sense. He would have understood the French words as meaning this or that, even though they meant something else. But given his ignorance of his misunderstanding, the target intuition about an experiential difference between he and Homer seems unaffected.

This is a familiar point in discussions of the target thought experiments. One way to highlight it would be to say that the target intuition is grounded in characters who have mental events (as) of understanding, where '(as)' functions to highlight that correctly understanding is not required. ${ }^{4}$ For our purposes the '(as)' convention risks getting cumbersome quickly. I will just stipulate that all talk of mental events of understanding in this essay takes the weaker, non-factive standard.

Second, there is a type of mental event of understanding that we should explicitly bracket aside. It seems possible to understand $\mathrm{C}$ as meaning $\mathrm{M}$ without being aware of doing so. ('Oh, I thought I wasn't understanding. But it turns out I was.'). This is not the ordinary case, of course. Usually if at $\mathrm{S}$ is understanding $\mathrm{C}$ as meaning $\mathrm{M}$, then at $\mathrm{t} S$ is aware of doing so. If this were not the ordinary case, we would not ordinarily move easily ahead to the next sentence in a novel while reading, for example. Generally speaking, when reading we need to see ourselves as understanding to move on. ${ }^{5}$

The second point to flag, then, is that we will only be concerned with mental events of understanding that satisfy the above awareness condition. We can put this by saying that all talk of mental events of understanding in this essay is talk of mental events of (aware) understanding. Bart and Apu are again exemplars here. They are not said to be in the odd position of failing to recognize that they have an understanding of the semantic items in front of them. This restriction to mental events of (aware) understanding is not usually noted in discussions of the above thought experiments. But its salience seems clear. The target intuition would surely not arise if we took Bart and Apu to be unaware of themselves as having an understanding of what is before them.

With these clarifications in hand, I can state my interests in this paper. My interests are with the following question about the target intuition: What explains why it can seem intuitive that there is, in some way, an experiential character to Bart and Apu's mental events of understanding that is absent from Homer and Lisa's mental lives? Despite the noted consensus, there is disagreement about this explanatory issue.

One way to cast this disagreement is to say that it is between Realists and AntiRealists about experiences of understanding. Roughly put, Realists (e.g., Galen Strawson, Charles Siewert, and David Pitt) try to explain the target intuition by

\footnotetext{
${ }^{4}$ Strawson $(2005,2011,1994)$ often uses basically this '(as)' convention. Strictly speaking, he uses it not to speak of mental events (as) of understanding but to speak of experiences (as) of understanding. But the convention plays the same role in both cases.

5 I have no particular account in mind of the awareness under discussion. But the operant sense of 'aware' is intended as relatively thin. For example, 'awareness' in this sense is more minimally involving than most senses of 'judges'. The latter term suggests an active reflective engagement, but the former suggests a more passive monitoring.
} 
positing a 'new' type of conscious experience. They propose that we cannot account for the target intuition without saying that just as people sometimes have, for example, visual experiences of blueness and headache experiences, so too people sometimes have experiences of understanding. In contrast, Anti-Realists (e.g., Jesse Prinz, Michael Tye, and William Robinson) propose that we can fully account for the target intuition without adding to the list of types of conscious experience. So Anti-Realists deny that we need to posit experiences of understanding to explain the target intuition. As Prinz puts it: "[T]he introspective intuitions are robust. But committed [Anti-Realists] need not surrender" (Prinz 2011, p. 188). ${ }^{6}$

My aim is to help move this debate between Realism and Anti-Realism forward. In the first half of this paper, I will try to get clearer on what the debate is about. What are Realists positing with experiences of understanding? What are AntiRealists proposing to do without? These questions have received some attention recently, and I will try to develop answers that extend and sharpen recent discussions. The goal is to deliver more precise characterizations of the above Realist and Anti-Realist views.

In the second half, I will turn from laying the terrain to planting a flag. I will argue that we are (defeasibly) justified in being Realists about experiences of understanding. Here too, though, I will often try to clarify the available positions in the debate at hand. As we will see, there are different ways to attempt Anti-Realist explanations of the target intuition. I will parse out and try to motivate several of these different ways, since that will lay a foundation for arguing that Realism better explains the target intuition than any of them does.

Before we start these projects, I should make two further notes. First, as I have framed things, Realists and Anti-Realists share the target intuition but depart on how to explain it. That means someone who denies the target intuition is not an Anti-Realist in my terminology. Although that may sound odd, this way of putting things should help keep clear that my interest is with a debate over competing explanations of the target intuition, rather than, say, with a debate about whether to grant that intuition. I will not argue for the target intuition itself. ${ }^{7}$

Second, it is worth flagging that there is a debate amongst Realists that I will be neutral on. Some Realists disagree about how to categorize experiences of understanding: Are they cognitive experiences or, instead, high-level sensory experiences? I have a view on this, but it is beside the point for this paper. ${ }^{8}$ The

\footnotetext{
${ }^{6}$ Prinz is actually speaking about both our target intuition and related intuitions about other 'phenomenal contrast' thought experiments. Realists are an example of what Prinz calls expansionists, and AntiRealists are an example of what he calls restrictivists - so 'Anti-Realists' replaces 'restrictivists' in the quote. Realists and Anti-Realists are also, respectively, examples of what Bayne (2009) calls phenomenal liberals and phenomenal conservatives.

7 Bayne and Montague (2011, p. 22) give one reason why some may want to deny the target intuition. It is possible to hold that the target intuition does not arise if we are careful to not mistake a non-experiential difference for an experiential difference, perhaps because of not mistaking non-experiential seemings for experiential seemings. Schwitzgebel (2008) discusses this general conceptual point about seemings, but the distinction dates to Chisholm (1957).

8 I develop my view in Dodd (ms.).
} 
present task of arguing for Realism is separate from and prior to the categorization task. $^{9}$

An analogy gives a nice way to illustrate this. Chemists occasionally discover new elements: e.g., the Curries with radium. As the periodic table of elements shows, sometimes these new elements can be categorized in illuminating ways. But there is an obvious priority relation between these tasks of discovery and categorization. Similarly, Realism about experiences of understanding proposes we should expand the list of types of conscious experience. How and whether this addition can be categorized insightfully is a distinct, further issue.

\section{Realism and Anti-Realism}

How can we more clearly parse out the debate between Realists and Anti-Realists? I suggest that the answer is to carefully move beyond an analogy that I used earlier. The analogy is what figured when I said Realists posit that just as we sometimes have, say, headache experiences and visual experiences of blueness, so too we sometimes have experiences of understanding.

I used this analogy because headache experiences and visual experiences of blueness are commonsense examples of types of conscious experience that we really have. For example, they do not seem to be mere gerrymandered constructs, conveniences of speech, or fabrications from false world-views. ${ }^{10}$ We can extrapolate from this analogy and say that Realists propose, but Anti-Realists deny, that experiences of understanding are among the types of conscious experience that we really have.

What I have in mind, then, is that we can better parse the debate between Realism and Anti-Realism if we can better track the commonsense concept of types of conscious experience that we really have. In particular, we can ask: What features does some set of mental events have to exhibit to count as a type of conscious experience that we really have? If we can answer that question, we can also answer: What features are Realists attributing to Bart's mental events of understanding by saying that he really has experiences of understanding?

To address these questions, I will start by distinguishing three concepts. Each of these concepts builds on the concept of experiential character. The general arc is that I will use these concepts to answer the above questions and to give refined statements of what Realism and Anti-Realism propose. We will also see that my refined statements directly develop how Siewert has recently framed the debate at issue.

\footnotetext{
9 For example, Pitt (2004) categorizes them as cognitive experiences and Siegel (2006) as high-level sensory experiences. Bayne and Montague (2011) summarize this categorization issue as follows: "Insofar as it is unclear just where (and how) to draw the line between thought and high-level perception... it will also be unclear whether a particular contrast argument [for Realism] would establish the existence of 'cognitive phenomenology' even if successful.... Opinions might differ as to whether understanding speech qualifies as a form of perception or thought" (p. 23).

${ }^{10}$ As an example of the latter: presumably no one really has experiences of the Fates smiling on them.
} 


\subsection{Kindred experiential character}

Take any mental events $\mathrm{e}_{1} \ldots \mathrm{e}_{\mathrm{n}}$. Let us say that $\mathrm{e}_{1} \ldots \mathrm{e}_{\mathrm{n}}$ share a kindred experiential character iff each among $e_{1} \ldots e_{n}$ has a similar experiential character to every other among $\mathrm{e}_{1} \ldots \mathrm{e}_{\mathrm{n}}$

The concept of kindred experiential character connects our ordinary concept of similarity with the concept of experiential character. To take one example, all visual experiences of blueness share a kindred experiential character. What it is like to have any particular visual experience of (any determinate shade of) blue is experientially similar to what it is like to have any other visual experience of (any determinate shade of) blue. ${ }^{11}$

Since similarity admits of degrees, the same goes for having a kindred experiential character. For example, there is an ordinary way of talking such that what it is like to have any headache experience is experientially similar to what it is like to have any other headache experience. So headache experiences share a kindred experiential character. But there is also a broader way of talking such that what it is like to have any pain experience is experientially similar to what it is like to have any other pain experience. So pain experiences share a kindred experiential character as well.

Of course, there are also plenty of mental events that do not share a kindred experiential character. For me, what is it like to have a headache experience is not experientially similar to what it is like to have any visual experience of blueness. Nor is what it is like to touch any piece of sandpaper experientially similar to what it is like to suck on a lemon. So my headache experiences and my visual experiences of blueness do not share a kindred experiential character. The same goes my experiences of touching sandpaper and my experiences of sucking lemons. ${ }^{12}$

\subsection{Exclusive experiential character}

Let us say that mental events $\mathrm{e}_{1} \ldots \mathrm{e}_{\mathrm{n}}$ share an exclusive experiential character iff each among $e_{1} \ldots e_{n}$ (a) has a similar experiential character to every other among $\mathrm{e}_{1} \ldots \mathrm{e}_{\mathrm{n}}$ and (b) has a different experiential character from every mental event not among $\mathrm{e}_{1} \ldots \mathrm{e}_{\mathrm{n}}$.

This concept builds directly on the concept of kindred experiential character. It uses a difference relation in addition to a similarity relation. ${ }^{13}$

\footnotetext{
11 See Hardin's (1988, pp. 40-45) discussion of the structure of phenomenal hues for interesting experiments about assessments of qualitative similarity amongst colours.

12 Kriegel (2009) argues that what it is like for someone to have a conscious experience is partly constituted by a feeling of for-me-ness. The idea is that what it is like for $\mathrm{S}$ to have, say, an experience of joy is partly constituted by S's feeling that this joy is her own. Kriegel's theory is notable because it implies that there is a sense in which all of S's experiences have a similar experiential character: they all share a feeling of for-me-ness. I will leave Kriegel's proposal aside. Readers who wish to can take my talk of similarity as talk of similarity beyond feelings of for-me-ness.

13 The concept of exclusive experiential character is closely related to Pitt's concept of proprietary phenomenology: any given type of conscious mental state has a proprietary phenomenology iff what it is like to be in it is "different from what it is like to be in any other sort of conscious mental state" (Pitt
} 
Each of our examples of mental events that share a kindred experiential character also share an exclusive experiential character. What it is like to have any headache experience is experientially different from what it is like to have anything other than a headache experience. Likewise, what it is like to have any particular visual experience of (any determinate shade of) blue is experientially different from what it is like to have anything other than a visual experience of (any determinate shade of) blue.

Here is an example of mental events that share a kindred experiential character but do not share an exclusive experiential character. Consider tactile experiences that we have when dipping an index finger in water that is exactly $20{ }^{\circ} \mathrm{C}$. These experiences share a kindred experiential character since they are all experientially similar. Indeed many such experiences will be maximally experientially similar, as many will be experientially identical.

But tactile experiences of dipping an index finger in $20{ }^{\circ} \mathrm{C}$ water do not share an exclusive experiential character. The reason is that their experiential character is the same as the experiential character of dipping an index finger in, say, $19.9^{\circ} \mathrm{C}$ water. After all, we each lack the tactile sensitivity to experience differences in temperature that tiny. (But if we had such incredible sensitivity, then our tactile experiences of dipping an index finger in $20^{\circ} \mathrm{C}$ water would share an exclusive experiential character). For humans then, tactile experiences of dipping an index finger in $20{ }^{\circ} \mathrm{C}$ water share a kindred experiential character but lack an exclusive experiential character. (To find what mental events in this vicinity do share an exclusive experiential character for some particular person, we would need to study that person's tactile sensitivity to temperature variation). ${ }^{14}$

\subsection{Basic experiential character}

Let us say that mental events $e_{1} \ldots e_{n}$ share a basic experiential character iff each among $e_{1} \ldots e_{n}(a)$ has a similar experiential character to every other among $e_{1} \ldots e_{n}$, (b) has a different experiential character from every mental event not among $\mathrm{e}_{1} \ldots \mathrm{e}_{\mathrm{n}}$, and (c) has a different experiential character from any group, complex, or sequence of (independently experienceable) conscious experiences that does not include any among $\mathrm{e}_{1} \ldots \mathrm{e}_{\mathrm{n}}$.

We can move in two steps to see what this concept involves. Our first focus will be all of condition (c) other than the bracketed content. The second focus will be what the bracketed content adds.

\footnotetext{
Footnote 13 continued

2004, p. 4). These concepts are also both related to Andre Gallois' concept of distinctive phenomenology: "Let us say that a psychological feature $\Phi$ has a distinctive phenomenology if and only if it satisfies the following condition. It is impossible for there to be no difference between what it is like to be $\mathrm{x}$ and what it is like to be $\mathrm{y}$ at some $\mathrm{t}$ unless $\mathrm{x}$ and $\mathrm{y}$ both have or lack $\Phi$ at t" (Gallois 1996, p. 18).

14 Hardin gives some other useful (and surprising) examples of experiences that fail to share an exclusive experiential character: "At very low frequencies, tactual feeling and hearing become so similar that in the $20 \mathrm{~Hz}$ region one is readily confused with the other. And when small puffs of air on the forehead are used to facilitate the subjective location of clicks that are fed to a subject through earphones, the puff is sometimes taken to be the click itself" (Hardin 1988, p. 133).
} 
The main content of (c) can be spoken to with contrasting examples. Start with headache experiences. If asked to describe the experiential character of my average headache, I would say things like 'It is a painful throbbing feeling that seems to be located in my head, above and behind my eyes'. If asked to say more, I may try to quantify its painfulness. But it would never seem fitting to analyze this experiential character in terms of some group, complex, or sequence of other experiences.

In contrast, consider mental events that are intuitively describable as experiences of swimming frontstroke. What it is like to swim frontstroke does seem to just be what it is like to have some sequence of other experiences. Specifically, it seems to be the same as what it is like to have the sequence of, for example, tactile and kinaesthetic experiences that one has upon performing the in-water movements that constitute swimming frontstroke. Similarly, what it is like to eat any particular fudge sundae seems to just be what it is like to have, for example, a particular group of taste sensations.

The upshot of these reflections is that my average headache experiences seem to share a basic experiential character, in addition to sharing an exclusive experiential character. But the same is not true for experiences of swimming frontstroke. Though they presumably share an exclusive experiential character, they do not share a basic experiential character. The same goes for experiences of eating any particular fudge sundae.

The example of experiences of swimming frontstroke will also help with clarifying the bracketed part of (c). Think again of the experiences that make up experiences of swimming frontstroke-for example, particular feelings of one's limbs and torso moving in-water in the manner of swimming frontstroke. A notable feature of these tactile and kinaesthetic experiences is that, at least to a coarse degree, each is independently experienceable. For example, a swim teacher could take a student's hand, guide it through the water in a particular way, and rightly say 'This is part of how your body should feel when you swim frontstroke'.

In contrast, consider visual experiences of blueness. We can analyze the experiential character of visually experiencing any determinate shade of blue in terms of experiencing the hue, saturation, and brightness of that shade. But we cannot independently experience the hue, saturation, and brightness of any shade of blue. Similarly, an auditory experience of a particular playing of middle $\mathrm{C}$ can be analyzed in terms of experiences of the pitch, timbre, and loudness of that sonic event. But we cannot independently experience any of those aspects of a playing of middle $\mathrm{C}$.

In short, the bracketed expression-'independently experienceable'-makes it so that (c) speaks to nuanced cases like colour and sound experiences. For example, it refines (c) such that visual experiences of blueness share a basic experiential character.

\subsection{Basic types of conscious experience}

Earlier I asked the question: What features does some set of mental events have to exhibit to count as a type of conscious experience that we really have? I think the above conceptual work suggests an answer: 
A set of mental events $\left\{\mathrm{e}_{1} \ldots \mathrm{e}_{\mathrm{n}}\right\}$ is a type of conscious experience that we really have iff (a) $e_{1} \ldots e_{n}$ share a basic experiential character and (b) at least some people token at least some of $\mathrm{e}_{1} \ldots \mathrm{e}_{\mathrm{n}} \cdot{ }^{15}$

The concept of basic experiential character is doing most of the work here. For short, then, we can say that the sets that are made up of mental events that satisfy the right-hand side of this biconditional are the basic types of conscious experience that we token.

Does anything recommend accepting this answer as a way to bring rigour to the commonsense idea of types of conscious experience that we really have? One source of support is that the technical concept seems to give the same results as commonsense. We can see this with our running examples. Commonsense says that we really have visual experiences of blueness and headache experiences. Both of these count as basic types of conscious experience. Similarly, I think commonsense agrees (or at least easily allows) that we are in the domain of conveniences of speech when we talk of experiences of swimming frontstroke, and that there is something gerrymandered about talk of experiences of dipping an index finger in exactly $20{ }^{\circ} \mathrm{C}$ water.

This said, I can imagine someone rejecting these claims about gerrymandering and conveniences of speech. For example, someone may object that commonsense demands that we really have experiences of swimming frontstroke, even though they lack a basic experiential character.

I do not find this objection attractive, but I will not try to argue against it. If the objection worked, all that would follow is that the concept of basic types of conscious experience that we token would be better taken as a hard-line or restrictive interpretation of our commonsense concept. As we will see, it is fine if it should be taken as such. ${ }^{16}$

\subsection{Realism and Anti-Realism clarified}

It is time to connect the preceding work to Realism and Anti-Realism about experiences of understanding. The easiest way to start this is to answer another question posed above: What features are Realists attributing to Bart's mental events of understanding by saying that Bart really has experiences of understanding? Using our conceptual repertoire, we can answer: Realists are attributing a basic experiential character to Bart's mental events of understanding.

\footnotetext{
${ }^{15}$ I am assuming, for simplicity, that a type is the set of its tokens. But for difficulties with this assumption, see Wetzel (2006).

16 As an aside, here is another feature of basic types of conscious experience. As we saw, we can distinguish broader and narrower kindred experiential characters: (more broadly) pain experiences share a kindred experiential character and (more narrowly) so do headache experiences. We can also distinguish broader and narrower basic types of conscious experience, since the concept of basic experiential character is built on the concept of kindred experiential character. The same examples show this: (more broadly) pain experiences are a basic type of conscious experience and (more narrowly) so are headache experiences. This flexibility seems in keeping with our ordinary way of talking of what types of conscious experience we really have.
} 
We can also say more precisely what Realism and Anti-Realism propose in response to the question that both aim to answer. That question was: What explains why it can seem intuitive that there is, in some way, an experiential character to Bart's mental events of understanding that is absent from Homer's mental life? Realism proposes that the explanation, at least in part, is that Bart tokens a basic type of conscious experience that Homer does not-specifically: Bart has an experience of understanding. Anti-Realism rejects that story. It proposes that other factors fully explain the target intuition.

There is still a hole in this characterization of the debate between Realism and Anti-Realism, of course. We can still ask: According to Anti-Realism, what are the other factors? The short story is that the different versions of Anti-Realism differ according to what they say these other factors are. I will start distinguishing versions of Anti-Realism shortly.

To review, at the start of this paper I gave rough characterizations of Realism and Anti-Realism about experiences of understanding. We have been trying to improve on those characterizations. To do so we examined broader conceptual issues surrounding the concept of experiential character. I have tried to use that conceptual work to create the more precise characterizations that we sought.

Before we move on, it remains to speak to a point introduced earlier. I said that my characterizations of Realism and Anti-Realism directly develop how Siewert casts these positions. Here is the connection:

Part of how Siewert gets clear on the sense in which he holds that we have experiences of understanding is by developing a contrast with experiences of eating durian fruit. He says: "It is plausible that what it's like to eat durian derives entirely from what it's like to have other features, having to do with the way durian tastes and smells, and how it feels in one's mouth" (Siewert 2011, p. 253). Then he writes:

It is not now disputed that there is positively something it's like for one ... to understand what one is saying, hearing, or reading as this happens-any more than it's disputed there is positively something it's like to eat durian. What's disputed is whether this [like what it's like to eat durian] derives entirely from what it's like to have concomitant, separable sensory features (Siewert 2011, p. 253).

There are three points to make about these remarks. First, since we just discussed the concept of basic experiential character, Siewert's analysis of experiences of eating durian should seem familiar. His durian example is like my examples of experiences of eating a particular fudge sundae and experiences of swimming frontstroke-that is, my examples of mental events that lack a basic experiential character.

Second, Siewert's notion of experiential character that 'derives entirely' from other experiential characters seems to function like the notion of lacking a basic experiential character. These ideas serve to distinguish the sense in which we have experiences of eating durian (or eating a particular fudge sundae, etc.) from the sense in which, according to Realists, we have experiences of understanding. 
These two points suggest that Siewert thinks of the commitments of Realism about experiences of understanding much the way that I have characterized them. ${ }^{17}$ But there is also a difference between Siewert's way of putting things and mine. The difference is not about how we should think of Realism, but how we should think of Anti-Realism. As I have said, I think that several explanatory options are available to Anti-Realists. In contrast, Siewert's way of framing the debate makes it sound as though there is just one Anti-Realist option-namely, to fully explain the target intuition in terms of "what it's like to have concomitant, separable sensory features". This form of Anti-Realism is the most prevalent in the literature, but we will see that other interesting options are available. ${ }^{18}$ So it seems helpful to think of Anti-Realism in the neutral manner that I suggested above.

\section{The significance of the debate between Realism and Anti-Realism}

On the heels of characterizing the debate between Realism and Anti-Realism, it makes sense to say why this debate is philosophically significant. I will identify just the biggest reason.

Two points are relevant to seeing the reason that I want to identify. First, it seems clear that the project of theorizing conscious experience depends on having a sense of what conscious experiences we really have. We need to know what we need to explain so we can try to explain it. Second, given this, the concept of basic types is relevant to determining the explanandum for theories of conscious experience. Specifically, the minimum explanandum ${ }^{19}$ for general theories of conscious experience $^{20}$ seems to be constituted by whichever basic types of conscious experience we token.

In light of these points, it is easy to see why the debate at hand matters. If the basic types of conscious experience constitute the minimum explanandum for theories of conscious experience, then the debate between Realism and AntiRealism is a debate about what figures in that explanandum. If Realism is true, experiences of understanding are part of the explanandum. In short, the biggest reason why this debate matters is it influences what any general theory of conscious experience needs to be a theory of. ${ }^{21}$

\footnotetext{
${ }^{17}$ I am not suggesting my conceptual work supplants Siewert's. Among other things, there is space between our efforts since Siewert begins by reconsidering the concept of there-is-something-it-is-likeness.

18 Siewert is discussing what I call Multitude Anti-Realism.

19 It is less clear that it constitutes the full explanandum for theories of conscious experience. For example, if the concept of basic types of conscious experience is a restrictive interpretation of which types of conscious experience we really have, then theories of conscious experience need to explain more than the basic types of conscious experience.

${ }^{20}$ We can, of course, theorize particular areas of conscious experience without giving a general theory of conscious experience. But many theories-e.g., many representationalist and higher-order theories-aim to be general theories of conscious experience.

21 Prinz puts this general point nicely in application to his own theory of conscious experience. Speaking of views like Realism, he writes: "If they are right, theories of consciousness that have been developed to
} 
It is worth flagging that the debate between Realism and Anti-Realism would be philosophically significant even if this was its only consequence. An analogy from earlier is useful again here. Discovering a new basic type of conscious experience seems broadly analogous to discovering a new chemical element. A discovery of the latter sort would be an intrinsically significant development in chemistry, if anything would. The same goes for experiences of understanding and philosophy of mind.

\section{An argument for Realism}

The remainder of this paper will be spent arguing for Realism. I will argue for the following claim:

Best Realism is the best explanation of why it seems intuitive that there is, in some way, an experiential character to (e.g.) Bart's mental event of understanding his target semantic item that is absent from Homer's mental life

By itself Best does not say that we are justified in believing Realism about experiences of understanding. But it does the heavy lifting towards that conclusion. To see this, just note that we can reasonably assume that: if Realism best explains the target intuition, we are (defeasibly) justified in believing Realism. We can assume this conditional because it is just an instance of the moderate version of inference to the best explanation. Moderate IBE infers from this explanans best explains that evidence to the epistemic conclusion that we are (defeasibly) justified in believing this explanans. This version of IBE is largely uncontroversial and a lynchpin of reasoning in the empirical sciences.

To argue for Best, I will look at four versions of Anti-Realism. I will argue that Realism explains the target intuition better than any of them does. As I noted earlier, the different versions of Anti-Realism tell different stories about what the other factors are that account for the target intuition. The first three Anti-Realist explanations are mainly views in logical space. It is mostly Multitude Anti-Realism, the fourth Anti-Realism we will discuss, that has been advocated to date. But since the debate between Realism and Anti-Realism is young, it is not surprising that there are more interesting Anti-Realisms than have been defended.

I will assume two rough principles to argue that Realism better explains the target evidence than these versions of Anti-Realism do. First, a principle of explanatory power: For any two explanans $\mathrm{x}$ and $\mathrm{y}$, and for any explanandum $\mathrm{z}$, $\mathrm{x}$ better explains $\mathrm{z}$ than $\mathrm{y}$ does if $\mathrm{x}$ explains more of $\mathrm{z}$ than $\mathrm{y}$. Second, a principle of explanatory

Footnote 21 continued

explain how perceptual states become conscious may not be adequate for explaining all aspects of consciousness. This would be a major setback for those of us who have invested in theories of perceptual consciousness with the hope that these theories can explain consciousness in general" (Prinz 2011, p. 174). 
expense: $\mathrm{x}$ better explains $\mathrm{z}$ than $\mathrm{y}$ does if $\mathrm{x}$ and $\mathrm{y}$ explain $\mathrm{z}$ to the same extent but $\mathrm{x}$ does so in, on the whole, a less costly way than y does.

Both of these principles are motivated by ordinary considerations. The principle of explanatory power captures the goal of comprehensiveness. It says, in effect, that $\mathrm{x}$ is a better explanation than $\mathrm{y}$ if $\mathrm{x}$ copes with more of the data to be explained. The principle of explanatory expense captures the idea that we ought to choose between explanations of equal power by weighing how big the bullets are that the different explanations make us bite. For our purposes, it is not necessary to create any rubric for weighing costs. When cost considerations come into play, it will be clear that Realism has a major advantage.

We can streamline arguing for Best by seeing what any Anti-Realism would need to be either equal or preferable to Realism in explanatory power or expense. In short, any Anti-Realism would need to (1) explain all our target evidence and (2) explain it in a low-cost way. It would need to do those things because Realism does those things:

(1) Clearly Realism can explain all the target evidence. It can explain it by positing experiences of understanding. (2) Realism's main cost is that it is less parsimonious than Anti-Realism. It is less parsimonious because it posits a basic type of conscious experience that Anti-Realism does not. But while parsimony costs are hardly trivial, they not only carry "the qualification 'others things being equal', but many, nearly all, other things must be equal before parsimony is called into break the tie" (Lycan 2009, p. 553). We will see that each Anti-Realism has costs that tip the scales for Realism before parsimony considerations enter the fray.

\section{Overestimation Anti-Realism}

The first version of Anti-Realism to consider is:

\section{Overestimation Anti-Realism}

It seems intuitive that there is an experiential character to Bart's mental events of understanding that is absent from Homer's mental life just because: we are disposed to overestimate the richness of the experiences that characters have in cases like the Bart scenario, especially in ways that feed on prominent psychological features of these characters (for example, that whereas Bart understands, Homer does not).

More simply put, Overestimation Anti-Realism proposes that the target intuition just tracks a context-sensitive disposition to overestimate in a particular way.

One way to try to motivate Overestimation Anti-Realism is to consider the socalled Grand Illusion. Proponents of the Grand Illusion argue for an analogue of Overestimation Anti-Realism in the domain of visual experience. Specifically, they argue that change blindness and inattentional blindness experiments show that our visual experiences are not as they intuitively seem to be. They propose that:

We believe that we see a complete, dynamic picture of a stable, uniformly detailed, and colourful world... [but] our stable visual world may be 
constructed out of a brief retinal image and a very sketchy, higher-level representation along with a pop-out mechanism to redirect attention. The richness of our visual world is, to this extent, an illusion (Blackmore et al. 1995, p. 1075).

So if proponents of the Grand Illusion are correct, some common intuitions about visual experience may be overestimations. Those intuitions may simply expose the average person's lack of knowledge about retinal images and pop-out effects. ${ }^{22}$

We will return to the link between the Grand Illusion and Overestimation AntiRealism shortly. But first I want to show that Overestimation Anti-Realism is a more costly explanation than Realism. I will focus on one cost of this Anti-Realism.

There is a tension between Overestimation Anti-Realism and a phenomenological principle that we seem to tacitly rely on. Call it the principle of modest realism about experiential differences:

Mod If it seems to me (or you, or any rational subject) that there is a difference between what it is like for me (or you, etc.) to token any two familiar types of mental events, then this seeming generally ought to be explained by positing that there actually is a difference between what it is like for me (or you, etc.) to token those types of mental events.

Two remarks are needed about Mod. First, it is modest in two ways. One is that it is restricted to familiar types of mental events. Which types of mental events are familiar will vary somewhat from person to person. The other is that Mod leaves room for exceptions. The strength of the explanatory claim is that we generally ought, not that we always ought. For example, Mod allows that Clancy might see himself as feeling different now — say, more cheerful — than he did one minute ago, but that in some cases this may be best explained by him introspecting lazily or having a bad short-term memory.

Second, we seem to rely on Mod in the sense that it seems implausible that we could function and flourish as we do without assuming it. Many day-to-day cases indicate this. For example, we seem to rely on this modest realism when we choose to head to the lavatory, since we do so upon assessing that how our bodies feel has changed in particular ways. We do not, in contrast, make such assessments but explain them away in an error theoretic fashion. Likewise, we seem to rely on this modest realism when we choose how to recreate (as well as what to eat, to drink, etc.). Such choices often involve assessments that, we assume, track differences in what seems pleasurable for us.

The tension between Mod and Overestimation Anti-Realism is clear. The target intuition is a seeming about experiential differences. But while Mod says that seemings about experiential differences between familiar types of mental events generally ought to be explained by positing actual experiential differences,

\footnotetext{
22 Although Prinz is a proponent of Multitude Anti-Realism (see later), sometimes his remarks gesture to Overestimation Anti-Realism. For example, when trying to explain why some are attracted to Realism, he writes: "the explanation on offer here is that introspection is subject to certain kinds of illusions, which lead us to posit features in experience that are not actually there” (Prinz 2011, p. 192).
} 
Overestimation Anti-Realism rejects this rule for the target intuition. It explains the target intuition not by positing experiential differences, but by positing a disposition to overestimate.

Can Overestimation Anti-Realism cope with this tension? The most promising option is to say that Overestimation Anti-Realism identifies an exception to Mod. But this strategy is unwarranted. If Mod is a general rule that we rely on, then exceptions to it ought to be granted only when independent evidence justifies them. Consider Clancy, again. It seems unwarranted to claim that he gets his assessment of an experiential difference wrong unless we have independent evidence to this effect-say, evidence that he has a bad short-term memory. But the trouble for Overestimation Anti-Realism is that it is hard to see any independent evidence that warrants granting it as an exception to Mod. So it seems hard to deny that the tension between Mod and Overestimation Anti-Realism is a genuine conflict.

In light of this, it seems implausible to motivate Overestimation Anti-Realism by appealing to the Grand Illusion. The disanalogy is that proponents of the Grand Illusion have evidence about retinal images and pop-out effects to buffer their explanation against phenomenological principles like Mod. Overestimation AntiRealism has nothing similar.

For our purposes the conflict between Mod and Overestimation Anti-Realism seems sufficient. The price of conflicting with a phenomenological principle that we rely on is much greater than Realism's cost in parsimony. Given our principle of explanatory expense, it follows that Realism better explains the target intuition than does Overestimation Anti-Realism.

\section{Ability Anti-Realism}

\section{A second Anti-Realism is:}

\section{Ability Anti-Realism}

It seems intuitive that there is an experiential character to Bart's mental events of understanding that is absent from Homer's mental life just because: Bart exercises an epistemic ability that Homer does not-specifically: Bart exercises his ability to understand the target semantic items, but Homer does not (since Homer lacks this epistemic ability).

Like Overestimation Anti-Realism, Ability Anti-Realism tries to explain the target intuition without positing any differences in conscious experiences. But it may seem a more promising way of making this move, since it appeals to a difference in exercised epistemic abilities, rather than an overestimation. This option may seem more attractive simply because there is a clear difference in what epistemic abilities the characters exercise. ${ }^{23}$

\footnotetext{
23 Ability Anti-Realism does not propose that we have different experiences when we exercise the relevant epistemic abilities. That tactic is compatible with both Realism and Anti-Realism. It is compatible with Realism if the experiences are said to be experiences of understanding. It is compatible with Anti-Realism if Anti-Realism is developed as either Singular or Multitude Anti-Realism. For
} 
To some extent, Ability Anti-Realism makes a similar move to what the Ability Hypothesis says about Frank Jackson's Mary Argument (Lewis 1988). Both propose that particular intuitions concerning conscious experiences can be explained by a difference in epistemic abilities. But there is a big difference between the Ability Hypothesis and Ability Anti-Realism. Whereas the former attempts to explain an intuition about differences in Mary's knowledge set, the latter attempts to explain an intuition about differences between experiences had by particular characters. But an appeal to the epistemological matter of differences in epistemic abilities is more at home explaining intuitions about differences in knowledge than intuitions about differences in experiences. So Ability Anti-Realism does not clearly gain any advantage from its link with the Ability Hypothesis.

What are the prospects of Ability Anti-Realism? They seem dim, since Ability Anti-Realism seems to conflict with Mod as much as Overestimation Anti-Realism does. Likewise, it seems unwarranted to say that Ability Anti-Realism is just an exception to Mod.

This conflict with Mod accounts for a gut reaction that some will have to Ability Anti-Realism. This version of Anti-Realism seems associable with a radical version of Rylean behaviourism (Ryle 1949). But having this association is a vice. There is a burden of justification on Ryleans that they have never been able to satisfy, and one branch of this burden is providing evidence to undermine phenomenological principles like Mod that we seem to rely on.

In sum, we gained more than insight on Overestimation Anti-Realism with Mod. That principle helps show the costliness of Ability Anti-Realism. But not all versions of Anti-Realism conflict with Mod. The remainder of this paper concerns Anti-Realisms that try to explain the target intuition by positing experiential differences between Bart and Homer, just not the experiential differences that Realism posits.

\section{Singular Anti-Realism}

To identify Singular Anti-Realism, it will help to create a shorthand. Call the uncontroversial examples of basic types of conscious experience: the canonical types of conscious experience. So, for example, pain experiences and visual experiences of blueness are canonical types of conscious experience.

\section{Singular Anti-Realism}

It seems intuitive that there is an experiential character to Bart's mental events of understanding that is absent from Homer's mental life because (i) there is one canonical type of conscious experience - namely, $X$ - that every person tokens during mental events of understanding any given semantic item, and (ii) Bart tokens $X$, but Homer does not.

\section{Footnote 23 continued}

example, it is compatible with Singular Anti-Realism if the experiences are said to be, say, experiences of familiarity. 
The immediate question for Singular Anti-Realism is whether there is any viable assignment for $X$. It is important to not understate this challenge:

On the one hand, $X$ must be a canonical type of conscious experience that is tokened by Bart, Apu, and any analogous character. Few canonical types pass this bar. Even just looking at Bart and Apu, most either are tokened by neither Bart nor Apu (e.g., neither is said to be sad or elated), or are not tokened by both Bart and Apu (e.g., only Bart is said to be having auditory experiences).

On the other hand, $X$ must fit the target intuition. For example, even if Bart and analogous characters all have experiences of agency or embodiment, it seems implausible to say that the target intuition tracks those experiences.

Are there any viable assignments for $X$ ? I suspect not, so I suspect Singular AntiRealism is mired from start. But it might seem that a viable assignment is emotional experiences of familiarity. We will assess this option and then look at another.

We can begin with a commonsense observation. When we talk about emotional experiences of familiarity, we ordinarily talk about experiences that we have upon seeing a friend or visiting somewhere we have frequented. So the version of Singular Anti-Realism we are considering depends on the ordinary cases being a small sub-set of our experiences of familiarity. After all, this version of Singular Anti-Realism claims that experiences of familiarity occur whenever individuals have the same type of mental event of understanding as individuals like Bart. Plausibly then, this version of Singular Anti-Realism strains our grip on experiences of familiarity.

This version of Singular Anti-Realism also faces a bigger problem. Even if we speak of experiences of familiarity more loosely, we do not seem to have them whenever we have the same type of mental event as Bart. For example, suppose that Patty hears the Sea Captain say 'Arrr, the sea is a hungry dog', and that Patty believes she has never heard this metaphor before. ${ }^{24}$ Suppose further that Patty understands the metaphor, just as Bart understands the sentences in the commercial. Does it seem required, or even likely, that Patty has an experience of feeling familiar with the Sea Captain's metaphor when she understands it?

My intuition is 'No'. It seems neither required nor likely. Indeed Patty may have an experience of feeling unfamiliar with the metaphor. More generally, the Patty scenario indicates that experiences of familiarity have more to do with recognizing the objects of our attention than with having an understanding of them.

Another potential way to cash out Singular Anti-Realism is to appeal to experiences of fluency. Does this assignment for $X$ fare better?

The first issue is to discuss experiences of fluency. These experiences have been talked about recently in circles in psychology (Reber et al. 2002). The idea that they may help explain the target intuition comes from Carruthers and Veillet (2011). When psychologists say that we have experiences of fluency, they seem to mean that we can have experiences of ease in the context of efforts of conceptual processing. For example, Bart may have an experience of fluency (ease of processing) when he

\footnotetext{
$\overline{24}$ This metaphor is from the poem 'The Sea' by James Reeves.
} 
hears the commercial, since he is encountering simple semantic items in a language in which he is fluent.

Much needs to be said about experiences of fluency before we should say that they are a basic type of conscious experience. But suppose that they are even a canonical type of conscious experience. Do they offer a viable assignment for $X$ ?

The answer seems to be 'No'. It seems implausible that individuals have experiences of fluency whenever they are in a similar mental event to Bart. For example, sometimes we encounter complex sentences-say, sentences of logicthat it is work to sort through. After we put that work in, we may well understand them. But there is no reason to think that we will have an experience of fluency (ease of processing) at that time. It was work to get to that point. It will probably feel accordingly.

In the end, Singular Anti-Realism does not seem to threaten Realism. There is no apparent way to develop it so that it has Realism's explanatory power.

\section{Multitude Anti-Realism}

The final Anti-Realism we will consider is:

\section{Multitude Anti-Realism}

It seems intuitive that there is an experiential character to Bart's mental events of understanding that is absent from Homer's mental life just because: Bart tokens any number of types of canonical experience that Homer does not token, since mental events of understanding any particular semantic items are apt to be accompanied by different canonical experiences than mental events of not understanding those semantic items.

Multitude Anti-Realism avoids the troubles of Singular Anti-Realism by casting a wider net. Whereas Singular Anti-Realism requires finding some canonical type of experience $X$ to do all of the explanatory work, Multitude Anti-Realism proposes that a variety of canonical types help to explain the target intuition. It also allows that from case to case different canonical types may do the explanatory work.

The main proponents of Multitude Anti-Realism are Jesse Prinz and Michael Tye. ${ }^{25}$ Here is Prinz:

If a monolingual English speaker hears the German word Hund it is just a sound. If a German speaker hears it, the experience is phenomenally different. ... [I]f we grant the two listeners have different phenomenal experiences, we can explain those differences [by appealing just to the following sorts of considerations]. The German speaker may form a visual image of a dog, or an auditory image of an associated word; she may have an emotional feeling of familiarity or recognition; she may form spontaneous motor images of dogrelated behaviors. Hearing familiar words triggers a cascade of responses,

\footnotetext{
${ }^{25}$ We might add William Robinson (2005). But I read Robinson as suggesting a hybrid of Ability AntiRealism and Multitude Anti-Realism that faces an amalgam of the problems for those views.
} 
documented through a thousand lexical priming studies, which may impact phenomenal experience (Prinz 2006, p. 452).

Prinz does not state his view in the generalized way that I have stated Multitude Anti-Realism. But my statement seems to capture what he and Tye advocate. ${ }^{26}$

There is something attractive about Multitude Anti-Realism. For example, it seems clear that Bart's linguistic competence might cause him to have different phoneme experiences than Homer. Similarly, Bart and Homer might have different imagery experiences, partly because their trains of thought may go different ways. Multitude Anti-Realism seems attractive because it highlights these sorts of experiences.

But this source of attraction is potentially misleading. What separates Realism from Multitude Anti-Realism is not that only the latter allows that Bart and Homer may have, for example, different phoneme and imagery experiences. Realism is silent about differences like these, but it allows that differences like these may be part of what explains the target intuition. What separates Realism from Multitude Anti-Realism is that while Realism says that we must posit experiences of understanding to explain the target intuition, Multitude Anti-Realism says that we need use only differences in canonical experiences.

A better reason to find Multitude Anti-Realism attractive may be the following. Since there are likely several differences in canonical experiences among the characters in our target thought experiments, it may seem that we need use only these differences to explain our target intuitions.

What should we make of this source of attraction? I think that it actually suggests how to see the problem with Multitude Anti-Realism. Suppose that we could create a version of our target thought experiments that generates the target intuition, but is not cluttered with differences that Multitude Anti-Realism can appeal to. If we could do this, it would show that differences in canonical experiences are insufficient to explain the target intuition. It would also respond to a challenge from Prinz:

[Realists] face the difficult challenge of having to find cases in which the phenomenal character of [understanding] transcends both of these rich sources ["verbal and non-verbal imagery"].... That challenge is very difficult to meet. I can think of no examples that are even plausible (Prinz 2011, p. 189). ${ }^{27}$

We can build on an example from earlier to create the requisite case. Suppose that Patty and Selma both hear the Sea Captain say 'Arrr, the sea is a hungry dog', and that each believes herself to have never heard this metaphor before. Suppose also that Patty has a mental event of understanding the metaphor, but that Selma

\footnotetext{
26 Tye makes similar remarks to Prinz in Tye (1996, p. 422).

27 As with the first quote from Prinz in this paper, I changed this passage to focus on our debate. Prinz's literal interest is the broader debate between (in his terminology) restricitivism and expansionism about conscious experience. The debate between Realism and Anti-Realism is an instance of that debate. Prinz's challenge applies as directly to our debate as to any region of the broader debate. The changes made are: 'Realists' for 'expansionists' and 'understanding' for 'thought'.
} 
does not. Does it seem intuitive that there is any difference between what conscious experiences Patty and Selma have when they hear the Sea Captain's utterance? ${ }^{28}$

On the one hand, this case seems to have the same core features as our initial thought experiments. In particular, if we agree that it seems intuitive that there is, in some way, an experiential character to Bart and Apu's mental events of understanding, then we can agree, presumably, that the same goes for Patty.

On the other hand, it is harder to see differences in canonical experiences between the characters in this case. There are no differences in phoneme experiences. Likewise, Patty and Selma may both have emotional experiences of feeling unfamiliar with the metaphor. It also seems that they can easily have the same imagery experiences: they may each picture a hungry dog and rolling seas, have associated motor sensations, and so on. But these imagery experiences can easily come just from having an understanding of the words uttered. It is hard to see what (and why) further imagery or emotional experiences must come with having an understanding of the metaphor uttered.

Are there any differences in canonical experiences that Multitude Anti-Realism can appeal to ${ }^{29}$ We can consider three possible approaches to this question.

First, Multitude Anti-Realism could reply that while it is not obvious what difference in imagery there is, we can suppose that there must be some difference since there is reason to favour an imagery theory of cognition. But this is not compelling. The focus of the most promising imagery theories of cognition is not mental imagery in our sense (e.g., that of mental pictures we can have when we close our eyes), but rather mental imagery in the sense of perceptual representations 'low-down' in our cognitive systems (Barsalou 1999). The question whether we experience changes in that sort of mental imagery is open.

Another reply is that Patty and Selma will have different imagery experiences because they will 'silently speak' different things when they hear the Sea Captain's utterance. The idea is that Patty will think something like 'I get it' while Selma will think something like 'What does that mean?'.

This is not compelling either. It seems exceptional for our inner monologues to speak up like this. Consider getting 'lost in fiction'. We can each immerse ourselves in novels rich with figurative language. But part of being immersed is reading without having one's internal monologue speak 'I get it' or 'What does that mean?' at every mental event of understanding or failing to understand. Maybe some people's inner monologues are rarely silent except when they are so immersed. But

\footnotetext{
${ }^{28}$ Other phrases we could use to the same end include: 'Light laughs the breeze in her castle of sunshine' (from Emily Dickeson's 'Safe in their alabastair chambers') or 'Love is the coal that makes this train roll' (from The Black Keys' 'Everlasting Light', Album: Brothers).

29 Earlier I said one criterion to complete the Singular Anti-Realist explanation is that candidate experiences must fit the target intuition. A similar point applies here. Multitude Anti-Realism cannot appeal to just any difference in canonical experiences, since it is not clear that doing so would speak to the target intuition. So Prinz seems mistaken when he says that to satisfy his challenge we need cases that, for example, "rule out the possibility of changes in non-verbal imagery" (Prinz 2011, p. 189, my italics). Perhaps that is needed for a full-stop proof against Multitude Anti-Realism, but not for challenging its fit and plausibility.
} 
this seems unlikely. I can hardly imagine having an inner monologue as active as this reply requires. ${ }^{30}$

This suggests two things about Patty and Selma. One is that it does not seem that they must 'silently speak' different things to themselves. The other is that since our inner monologues are likely less active than this reply requires, it seems implausible to explain our intuitions by saying that we ascribe silent speech-based experiential differences.

A third reply is that Patty and Selma will have different imagery experiences because their different levels of understanding will send their trains of thought in different directions. The idea is that Patty will go in directions-say, thinking about the sea's voraciousness - that Selma will not.

But again, this is not compelling. More than levels of understanding will influence what directions Patty and Selma's thoughts go. Influences will include how interesting each finds the metaphor and contextual factors competing for their attention.

Also, we can amend the Patty and Selma case to show that this third reply does not suffice. Keep the details the same, but add that an airplane flies overhead after the Sea Captain's utterance. Suppose that its sound grabs Patty and Selma's attention, turning each from considering the metaphor in ways beyond just understanding it or not. In this case, it still seems that Patty differs experientially from Selma. It still seems that there is, in some way, an experiential character to Patty's mental event of understanding the metaphor. What is new is that there are new similarities between Patty and Selma. For example, each will have a sharp auditory experience.

In sum, the Patty and Selma case seems to weigh against Multitude AntiRealism. The target intuition does not only arise for cases that are cluttered with the sorts of differences that Multitude Anti-Realism appeals to. It follows that Multitude Anti-Realism lacks Realism's explanatory power.

Also, the Patty and Selma case indicates that though Multitude Anti-Realism has received the most attention amongst Anti-Realisms, this is not clearly warranted. Its prominence may be mainly an effect of its wide net tactic and contingencies of the Bart and Apu cases that risk encouraging that tactic.

\section{Conclusion}

There are several ways to try to explain the intuitions that are the target of this paper. I have distinguished five: Realism about experiences of understanding and four versions of Anti-Realism. I have argued that we are justified in believing Realism. My attention has been on arguing for Best, the claim that Realism best explains the target intuition. But given moderate IBE, a successful defence of Best

\footnotetext{
30 Siewert gives extensive responses to the 'silent speech' idea in his 1998 and 2011. I address it only briefly because of his discussion, and because the move seems untenable for the given reason. But I wonder whether part of what lies behind disagreement over the 'silent speech' idea is differences from person to person in how active our inner monologues are.
} 
entails that we are justified in believing that, as Realism proposes, experiences of understanding are a basic type of conscious experience.

I see this case for Realism as a step towards a full theory of experiences of understanding. Lots of work remains. For example, there is the categorization question that I put aside early in this paper. We are better positioned to work on such issues if we now have a better grasp of what Realism proposes and why we should believe it.

Acknowledgments This paper descends from material in my Ph.D. dissertation at Syracuse University. Thanks to Bob Van Gulick, Bence Nanay, Kris McDaniel, Andrew Brook, and André Gallois for their support during my dissertation process. I presented an earlier version of this paper at the departmental colloquium at Carleton University. Thanks to those present, especially Dave Matheson, for helpful discussion. And, of course, thanks to Matt Groening (the creator of The Simpsons) for his cast of characters.

\section{References}

Barsalou, L. (1999). Perceptual symbol systems. Behavioral and Brain Sciences, 22, 577-660.

Bayne, T. (2009). Perceptual experiences and the reach of phenomenal content. Philosophical Quarterly, 59, 385-404.

Bayne, T., \& Montague, M. (2011). Introduction. In T. Bayne \& M. Montague (Eds.), Cognitive phenomenology (pp. 1-34). Oxford: Oxford University Press.

Blackmore, S. J., Brelstaff, G., Nelson, K., \& Troscianko, T. (1995). Is the richness of our visual world an illusion? Transsaccadic memory for complex scenes. Perception, 24, 1075-1081.

Carruthers, P., \& Veillet, B. (2011). The case against cognitive phenomenology. In T. Bayne \& M. Montague (Eds.), Cognitive phenomenology (pp. 35-56). Oxford: Oxford University Press.

Chisholm, R. (1957). Perceiving. Ithaca, NY: Cornell UP.

Dodd, J. (ms.). Experiences of understanding and the question of cognitive phenomenology.

Gallois, A. (1996). The mind without, the world within: An essay on first-person authority. Oxford: Oxford University Press.

Hardin, C. (1988). Color for philosophers (Expanded ed.). Indianapolis, IN: Hackett Publishing.

Horgan, T., \& Tienson, J. (2002). The Intentionality of Phenomenology and the Phenomenology of Intentionality. In D. Chalmers (Ed.), Philosophy of mind: Classical and contemporary readings (pp. 520-533). Oxford: Oxford University Press.

Kriegel, U. (2009). Subjective consciousness: A self-representational theory. Oxford: Oxford University Press.

Lewis, D. (1988). What experience teaches. Proceedings of Russellian Society, 13, 29-57.

Lycan, W. (2009). Giving dualism its due. Australasian Journal of Philosophy, 87, 551-563.

Peacocke, C. (1992). A study of concepts. Cambridge, MA: MIT Press.

Pitt, D. (2004). The phenomenology of cognition-Or, what is it like to think that P? Philosophy and Phenomenological Research, 69, 1-36.

Prinz, J. (2006). Beyond appearances: The content of sensation and perception. In T. Gendler \& J. Hawthorne (Eds.), Perceptual experience (pp. 434-460). Oxford: Clarendon Press.

Prinz, J. (2007). All consciousness is perceptual. In B. McLaughlin \& J. Cohen (Eds.), Contemporary debates in philosophy of mind (pp. 335-357). Oxford: Blackwell.

Prinz, J. (2011). The sensory basis of cognitive phenomenology. In T. Bayne \& M. Montague (Eds.), Cognitive phenomenology (pp. 174-196). Oxford: Oxford University Press.

Reber, R., Fazendeiro, T. A., \& Winkielman, P. (2002). Processing fluency as the source of experiences at the fringe of consciousness. Psyche, 8, 10. http://psyche.cs.monash.edu.au/v8/psyche-8-10reber.html.

Robinson, W. (2005). Thoughts without distinctive non-imagistic phenomenology. Philosophy and Phenomenological Research, 70, 534-561.

Ryle, G. (1949). The concept of mind. London: Hutchinson. 
Schwitzgebel, E. (2008). The unreliability of naïve introspection. The Philosophical Review, 177, $245-273$.

Siegel, S. (2006). What properties are represented in perception? In T. Gendler \& J. Hawthorne (Eds.), Perceptual experience (pp. 481-503). Oxford: Clarendon Press.

Siewert, C. (1998). The significance of consciousness. Princeton, NJ: Princeton University Press.

Siewert, C. (2011). Phenomenal thought. In T. Bayne \& M. Montague (Eds.), Cognitive phenomenology (pp. 236-267). Oxford: Oxford University Press.

Strawson, G. (1994). Mental reality. Cambridge, MA: MIT Press.

Strawson, G. (2005). Intentionality and experience: Terminological preliminaries. In D. W. Smith \& A. Thomasson (Eds.), Phenomenology and philosophy of mind (pp. 41-66). Oxford: Oxford UP.

Strawson, G. (2011). Cognitive phenomenology: Real life. In T. Bayne \& M. Montague (Eds.), Cognitive phenomenology (pp. 285-325). Oxford: Oxford University Press.

Tye, M. (1996). Mental reality. Journal of Philosophy, 93, 421-424.

Wetzel, L. (2006). Types and tokens. Stanford encyclopedia of philosophy. http://plato.stanford.edu/ entries/types-tokens/. 